\title{
Desordens nutricionais provocadas por deficiência e excesso dezinco em plantas de milho
}

\author{
Nutritional disorders caused by deficiency and excess of zinc in maize \\ plants
}

\author{
Willian Tsuyoshi KUME ${ }^{1}$; Luana Marques CAMPOS $^{2}$; Rômulo RIBEIRO ${ }^{3}$; Gustavo CAIONE ${ }^{4}$ \\ Autor para correspondência, Mestre, Universidade do Estado de Mato Grosso - Câmpus Alta Floresta, \\ williankume@hotmail.com \\ ${ }^{2}$ Mestre, Universidade do Estado de Mato Grosso - Câmpus Alta Floresta, luanamarquescampos@hotmail.com \\ ${ }^{3}$ Engenheiro Agrônomo, Universidade do Estado de Mato Grosso - Câmpus Alta Floresta, romuloribeirotec@outlook.com \\ ${ }^{4}$ Doutor em Agronomia, Universidade do Estado de Mato Grosso - Câmpus Alta Floresta, gcaione@unemat.br
}

Recebido em: 28-05-2021; Aceito em: 14-10-2021

\begin{abstract}
Resumo
Sabe-se a importância do fornecimento adequando de zinco (Zn) no desenvolvimento inicial da cultura do milho, dessa forma conhecer os sintomas de deficiência e de excesso bem como a interação do micronutriente com outros elementos é essencial. Objetivou-se avaliar concentrações de $\mathrm{Zn}$ em solução nutritiva na nutrição e no desenvolvimento inicial da cultura do milho. Utilizou-se delineamento inteiramente casualizado com quatro concentrações de $\mathrm{Zn}$ : $0 ; 0,733 ; 1,465 ; 2,930$ ou $5,861 \mu \mathrm{mol} \mathrm{L} \mathrm{L}^{-1}$. Após 30 dias, avaliou-se o comprimento de parte aérea e raiz, diâmetro de colmo, volume de raiz, massa seca de parte aérea e de raiz e teor micronutrientes (zinco, manganês $(\mathrm{Mn})$, ferro $(\mathrm{Fe})$ e boro $(\mathrm{B})$ ). Evidenciou-se que a ausência de zinco na solução nutritiva resultou em menor crescimento da planta e sintomas visuais de deficiência. Estes resultados contribuem para a diagnose foliar a campo de forma a identificar a deficiência nos estágios iniciais do crescimento da cultura. Além disso, verificou-se interações com outros nutrientes, havendo relação inversa entre teores foliares de $\mathrm{Mn}$, Fe e B com teores de Zn. Este resultado demonstra o desbalanço nutricional provocado tanto pela ausência quanto pelo excesso de zinco e sugere uma possível interação ainda não conhecida com o B.
\end{abstract}

Palavras-chave adicionais: diagnose foliar; inibição competitiva; nutrição de plantas

\begin{abstract}
The importance of an adequate supply of zinc (Zn) in the initial development of the maize crop is well known, so it is essential to be aware of the symptoms of deficiency and excess, as well as the interaction of the micronutrient with other elements. Thus, the objective of the present work was to evaluate the effect of zinc concentration in nutrient solution on the nutrition and initial development of the maize crop. An entirely randomized design was used with four Zn concentrations: $0 ; 0.733 ; 1.465 ; 2.930$ or $5.861 \mu \mathrm{mol} \mathrm{L}^{-1}$. After 30 days shoot and root length, stem diameter, root volume, shoot and root dry matter and micronutrient content (zinc, manganese $(\mathrm{Mn})$, iron (Fe) and boron (B)) were evaluated. It was evident that the absence of $\mathrm{Zn}$ in the nutrient solution resulted in less plant growth and visual deficiency symptoms. These results contribute to field foliar diagnosis in order to identify deficiency at early stages of crop growth. Furthermore, interactions with other nutrients were found, with an inverse relationship between leaf levels of $\mathrm{Mn}, \mathrm{Fe}$ and $\mathrm{B}$ with $\mathrm{Zn}$ content. This result demonstrates the nutritional imbalance caused by both the absence and excess of zinc and suggests a possible interaction not yet known with $\mathrm{B}$.
\end{abstract}

Additional keywords: competitive inhibition; leaf diagnosis; plant nutrition. 


\section{Introdução}

O desbalanço nutricional decorrente da deficiência ou excesso de zinco $(\mathrm{Zn})$ na cultura do milho é um dos fatores mais limitantes para o seu desenvolvimento adequado. A cultura é sensível a deficiência do micronutriente e quando insuficiente acarreta em prejuízos no crescimento da planta, perdas na produtividade e grãos de baixa qualidade para consumo humano e animal (Singh et al., 2005).

Os sintomas de deficiência já são aparentes durante o crescimento inicial e geralmente é marcada pelo menor crescimento da planta (internódios mais curtos) e aparecimento de manchas marromesbranquiçadas nas folhas novas podendo se tornar necróticas em casos extremos (Singh et al., 2005).

Por outro lado, o excesso de $\mathrm{Zn}$, decorrente principalmente do descarte inapropriado de rejeitos industriais, também está associado com menor produtividade e crescimento de plantas e raízes devido ao desbalanço nutricional. Nesta condição há o surgimento de clorose paralelas à nervura central e diminuição da massa seca devido ao comprometimento da integridade das membranas celulares pela excessiva produção de espécies reativas de oxigênio levando ao estresse oxidativo (Islam et al., 2014).

Além disso, estudos relatam a influência do teor de Zn no solo sobre a absorção de outros micronutrientes. A correlação inversamente proporcional de $\mathrm{Zn}$ e $\mathrm{Fe}$ em folhas devido à similaridade entre os raios atômicos, assim competindo pelo mesmo sítio de absorção, são descritas na literatura em plantas de trigo e milho, no entanto, a relação de outros micronutrientes ainda são escassas (Gupta et al., 2016; Imtiaz et al., 2003; Kanai et al., 2009).

Nota-se, ainda, que 0 teor ideal do micronutriente na cultura ainda é amplamente discutida na literatura, sendo que Galrão et al. (1994) e Rosolem et al. (1998) obtiveram teor ideal de $14 \mathrm{mg}$ $\mathrm{kg}^{-1}$, enquanto que o teor adequado obtido por Fageria (2000) foi de $27 \mathrm{mg} \mathrm{kg}^{-1}$ e por Leite et al. (2003) foi de 34,07 a $175,16 \mathrm{mg} \mathrm{kg}^{-1}$.

Adicionalmente, experimentos onde há aplicação de altas doses de $\mathrm{Zn}$ os sintomas visuais de toxidade são ausentes mesmo em teores foliares do micronutriente de $427 \mathrm{mg} \mathrm{kg}^{-1}$ (Fageria, 2000); 359,67 $\mathrm{mg} \mathrm{kg}^{-1}$ (Leite et al., 2003) e $322 \mathrm{mg} \mathrm{kg}^{-1}$ (Amaral et al., 1996), há, todavia, diminuição da massa seca. Segundo Botoman et al. (2020) e Eteng et al. (2017) a diferença dos valores com relação ao teor adequado de $\mathrm{Zn}$ em milho como também o nível tóxico pode ser atribuído a variação do $\mathrm{pH}$ e ao tipo de solo utilizado, uma vez que são fatores que afetam diretamente a disponibilidade do micronutriente.

Neste contexto, experimentos conduzidos em solução nutritiva podem contribuir para um melhor entendimento da relação do teor de $\mathrm{Zn}$ com os sintomas tanto de excesso como de deficiência, bem como a interação do micronutriente com outros elementos (Broadley et al., 2006).

Neste tipo de sistema isso é possível pela possibilidade de melhor controle da concentração dos nutrientes fornecidos visto que estão prontamente disponíveis para a absorção e de forma homogênea para as plantas (Gondim et al., 2016). Em solo, por outro lado, a biodisponibilidade dos nutrientes varia de acordo como tipo de solo e também à medida que os elementos vão se ligando às partículas do solo cria-se microambientes heterogêneos. Além disso, o estudo da parte radicular é facilitado em solução nutritiva pois diminui os possíveis danos mecânicos das raízes laterais que podem ocorrer num experimento em solo (Nguyen et al., 2016).

Assim, objetivou-se avaliar concentração de Zn em solução nutritiva na nutrição e no desenvolvimento inicial da cultura do milho.

\section{Material e métodos}

O experimento foi realizado na Universidade do Estado de Mato Grosso, Câmpus de Alta Floresta MT. Conduziu-se em ambiente protegido, coberto com filme plástico difusor de luz $(150 \mu \mathrm{m})$ e com telado lateral e frontal de $50 \%$ de sombreamento. Utilizou-se o delineamento inteiramente casualizado (DIC) realizando o rodízio dos vasos em quatro repetições sendo três plantas para compor uma repetição.

Inicialmente as sementes de milho, híbrido MG-618 da Morgan Sementes, foram semeadas em bandeja de poliestireno, contendo 0 substrato comercial e regado diariamente de forma manual. Após 15 dias, as mudas foram retiradas da bandeja, lavando-se as raízes com água destilada para a retirada do substrato e transplantadas para vasos com capacidade para $7 \mathrm{~L}$. As plantas foram ancoradas em placas de poliestireno e colocadas sobre a solução nutritiva.

A solução nutritiva utilizada foi baseada na de Hoagland \& Arnon (1950) onde foi adaptada a concentração com $\mathrm{Zn}$, na qual utilizou-se como fonte de $\mathrm{Zn}$ o sulfato de zinco $\left(\mathrm{ZnSO}_{4}\right)$. A partir da solução estoque $\left(0,7326 \mathrm{mmol} \mathrm{L}^{-1}\right.$ de $\left.\mathrm{Zn}\right)$ alíquotas de $0,1,2,4$ ou $8 \mathrm{~mL} \mathrm{~L}^{-1}$ de solução nutritiva foram adicionadas aos vasos para compor os tratamentos, os valores equivalem respectivamente a $0 ; 0,733$; 1,$465 ; 2,930$ ou $5,861 \mu \mathrm{mol} \mathrm{L}-1$. As concentrações foram dobradas consecutivamente tendo como ponto de partida a recomenda por Hoagland \& Arnon (1950), 0,733 $\mathrm{mol} \mathrm{L}^{-1}$.

$\mathrm{O}$ Fe também foi adaptado utilizando $\mathrm{Fe}$ quelatizado comercial (QuelMax-Fe EDDHA) na mesma concentração indicada na solução original.

Para oxigenação da solução, utilizou-se compressores de ar do tipo bombas de aquário Master Super II $(5 \mathrm{~W})$ de 2 saídas. $\mathrm{O} \mathrm{pH}$ foi monitorado diariamente com o auxílio de medidor de $\mathrm{pH}$ portátil, mantendo entre 5,8 e 6,2, com o uso de $\mathrm{HCl}$ e $\mathrm{NaOH}$ $0,5 \mathrm{M}$ para $\mathrm{O}$ ajuste. Inicialmente a água 
evapotranspirada foi reposta com água deionizada Houve a renovação completa da solução nutritiva após 15 dias ao transplantio das mudas, quando o volume evapotranspirado atingiu $1 / 3$ da capacidade do vaso.

Ao fim do experimento, 30 dias após 0 transplantio avaliou-se o comprimento da parte aérea e comprimento do sistema radicular, medido com auxílio de trena; diâmetro de colmo, mensurado com paquímetro digital e volume de raiz, medido através do volume de água deslocado em proveta contendo 100 $\mathrm{mL}$ de água destilada e submersão do sistema radicular.

As amostras foram secas em estufa de ventilação forçada à $70^{\circ} \mathrm{C}$ até a obtenção de massa constante. Após este período foram pesadas, em balança analítica, para a obtenção da matéria seca da parte aérea e raiz e moídas em moinho Willey. Em seguida, foram determinados os teores de micronutrientes em toda planta $(\mathrm{Zn}, \mathrm{Mn}, \mathrm{Fe}$ e B), seguindo a metodologia descrita por Silva (2009).

Os dados obtidos foram submetidos a análise de variância pelo teste $\mathrm{F}$ e teste de regressão polinomial, utilizando o programa estatístico Sisvar (Ferreira, 2011). As figuras foram confeccionadas com auxílio do programa Origin 9, escolhendo o modelo significativo e que apresentou melhor ajuste aos dados. $\mathrm{O}$ ajuste dos modelos aos dados foi realizado com base nos seguintes critérios: coeficiente de determinação ajustado, sendo considerado como melhor aquele modelo que forneceu o maior valor e o valor de Akaike (AIC), que indica como melhor modelo aquele que apresenta os menores valores (Fernandes et al., 2014).

\section{Resultados e discussão}

As concentrações de $\mathrm{Zn}$ promoveram efeito sobre o teor do micronutriente na planta (Figura $1 \mathrm{~A}$ ). O maior teor de $\mathrm{Zn}$ encontrado foi na dose de 4,964 $\mu \mathrm{mol} \mathrm{L}^{-1}$ com $52,65 \mathrm{mg} \mathrm{kg}^{-1}$ de $\mathrm{Zn}$, indicando que a partir desta dose o nível de toxicidade é atingido e, consequentemente, o teor do micronutriente tende a estabilizar e posteriormente cair.
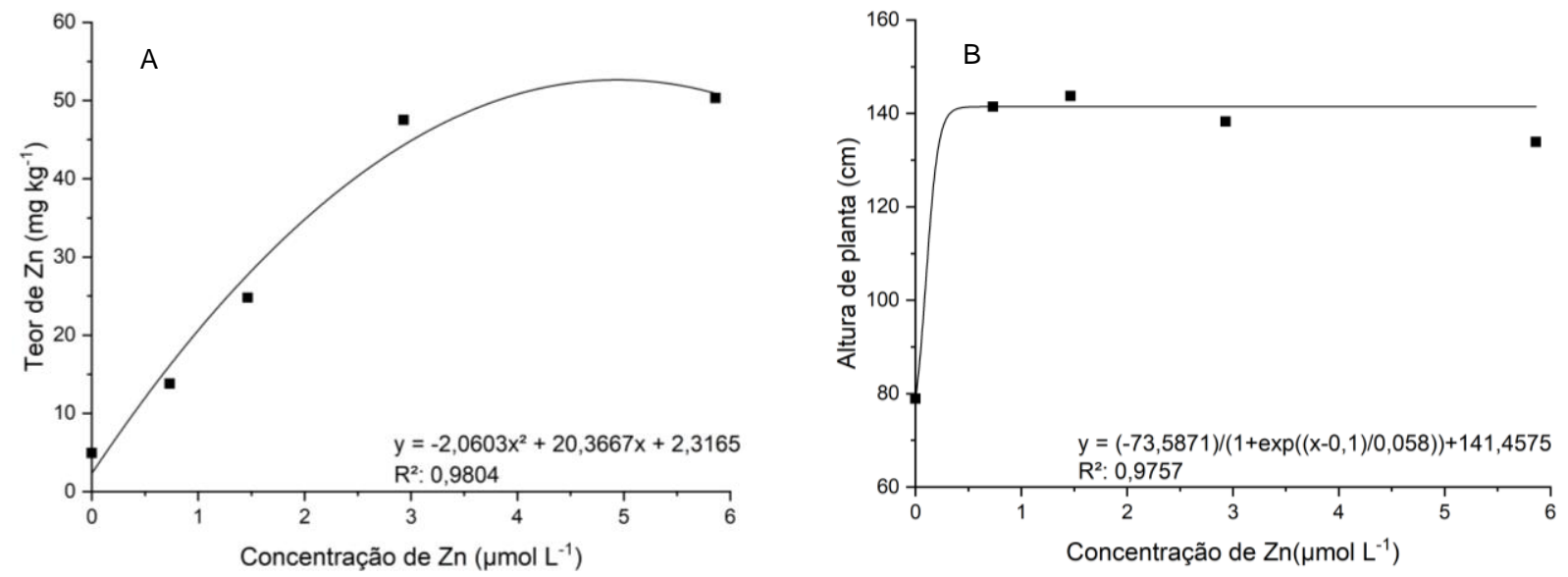

Figura 1 - Teor de Zn na massa seca $(A)$ e altura de plantas de milho (B), em função das concentrações de $\mathrm{Zn}$. Zn content in dry mass $(A)$ and height of maize plants $(B)$, as a function of $Z n$ concentrations.

A variável altura de planta (Figura 1 B) se ajustou ao modelo de Boltzmann; a massa seca da parte aérea e diâmetro de colmo ao modelo polinomial (Figura 2 A e B). É possível notar, de modo geral que, na ausência de aplicação de $Z n$ todas as variáveis são severamente afetadas, demonstrando menores valores e, a partir da primeira concentração, os valores das variáveis já se elevam, mantendo-se semelhantes até na maior concentração, onde a partir dessa já demonstram tendência de queda, o que indica excesso de $\mathrm{Zn}$.

A altura de planta na concentração de 0,733 umol L-1 (Figura 1 B) foi de $141,46 \mathrm{~cm}$ e ao observar o os pontos seguintes percebe-se não houve diferença expressiva. Este fato indica que a concentração de Zn é adequada para suprir a necessidade do micronutriente na planta, não sendo necessário maiores aplicações.

Os maiores valores para as variáveis massa seca da parte aérea $(9,52 \mathrm{~g})$ (Figura 2 A) e diâmetro de colmo (12,61 mm) (Figura $2 \mathrm{~B}$ ) foram encontrados nas concentrações de 2,11 e $1,96 \mu \mathrm{mol} \mathrm{L}^{-1}$ respectivamente. Para essas variáveis citadas anteriormente foi possível observar a manifestação do efeito fitotóxico. Verificou-se queda nas maiores concentrações quando comparadas com a indicada por Hoagland Arnon (1950) de 0,733 $\mathrm{mmol} \mathrm{L}^{-1}$. Dessa forma, o diâmetro do colmo foi uma variável de crescimento que interferiu no acúmulo de massa seca, afetando de forma mais expressiva que a altura de plantas. 

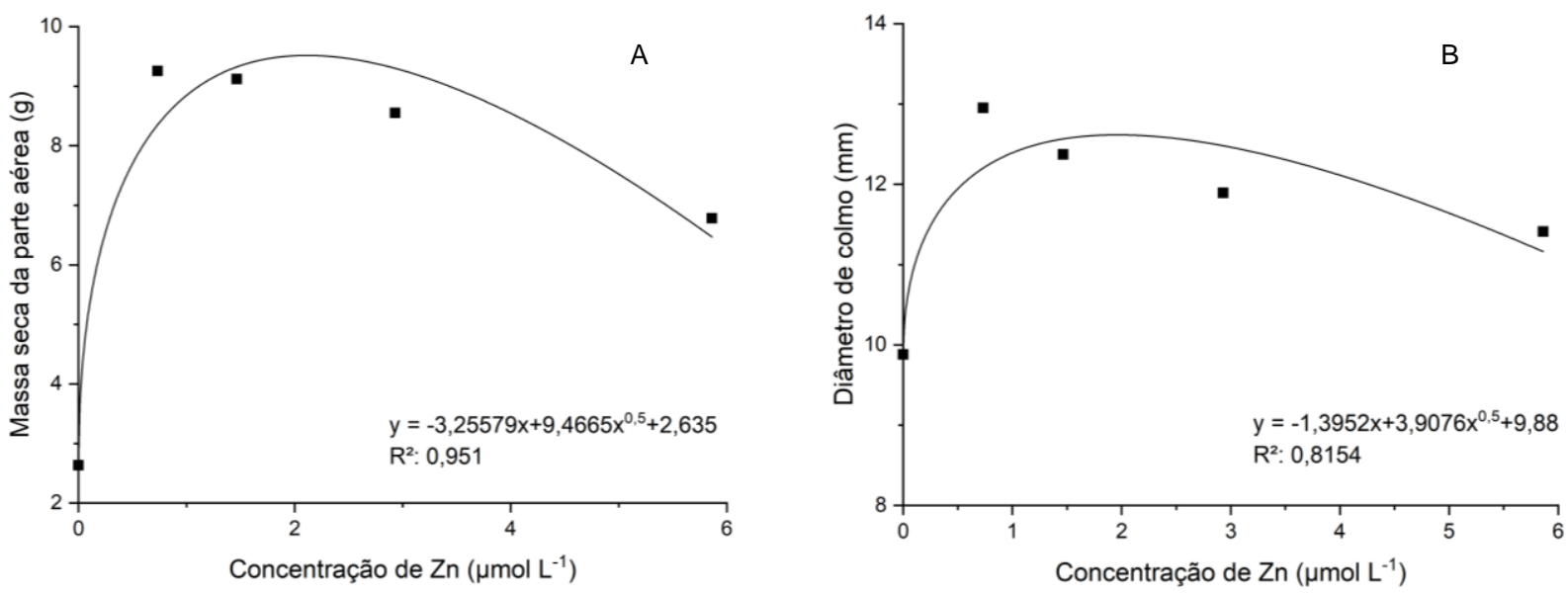

Figura 2 - Massa seca da parte aérea (A) e diâmetro de colmo de plantas de milho (B), em função das concentrações de $\mathrm{Zn}$. Shoot dry mass (A) and stem diameter of maize plants (B), as a function of $\mathrm{Zn}$ concentrations.

Ressalta-se que sintomas de excesso de $\mathrm{Zn}$ difere em cada estágio de crescimento da planta e da espécie e, de forma geral, está associado com prejuízos na produtividade, menor crescimento de planta e raiz (Hosseini et al., 2013).

A queda no diâmetro de colmo e, consequentemente, na massa seca da parte aérea na maior dose pode estar relacionado à deficiência de $\mathrm{Fe}$ e Mn, uma vez que, apresentam raios atômicos semelhantes ao $\mathrm{Zn}$. Sabe-se que o excesso de um nutriente pode provocar a inibição competitiva na qual a absorção e translocação de outros nutrientes que

A

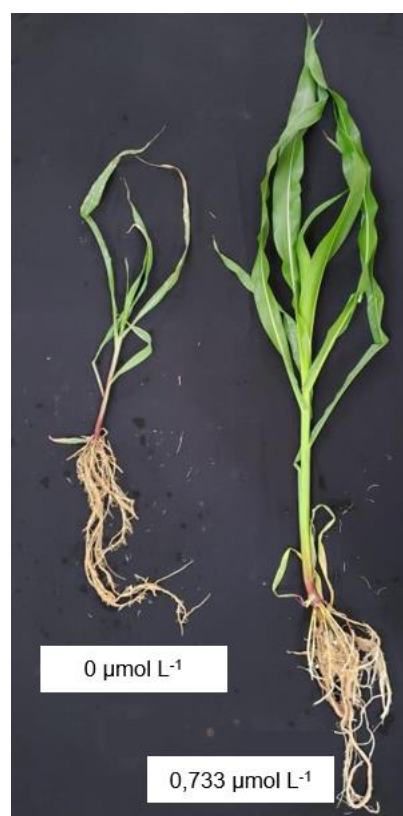

utilizam o mesmo sítio de absorção é prejudicada (Mousavi et al., 2012).

O menor valor encontrado na ausência do micronutriente para as variáveis apresentadas anteriormente (altura de planta, massa seca da parte aérea e diâmetro de colmo) está associado com menor síntese de AIA o que resulta em encurtamento dos internódios e menor área foliar (Erturk, 2015), além disso foi possível observar partes necróticas nas folhas, possivelmente, devido ao acúmulo de espécies reativas de oxigênio, como pode ser observado na Figura 3.

\section{B}

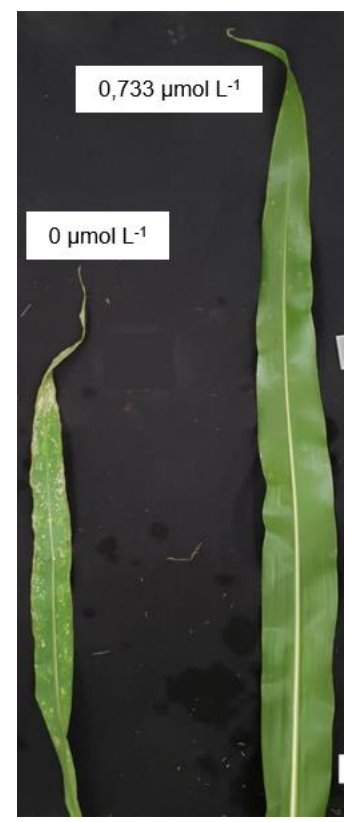

Figura 3 - Comparação entre plantas (a) e folhas novas de milho (b) sob os tratamentos sem Zn (esquerda) e completo $\left(0,773 \mu \mathrm{mol} \mathrm{L}^{-1}\right)$ (direita). Foto: Willian Tsuyoshi Kume. Comparison between plants (a) and young maize leaves (b) under the treatments without $\mathrm{Zn}$ (left) and complete $\left(0.773 \mu \mathrm{mol} L^{-1}\right)$ (right). Photo: Willian Tsuyoshi Kume 
Para o volume de raiz (Figura $4 \mathrm{~A}$ ) o maior valor foi de $33,19 \mathrm{~cm}^{3}$ na concentração de 2,13 $\mu \mathrm{mol} \mathrm{L}^{-1}$. No entanto, quando avaliado o comprimento de raiz (Figura 4 B) obteve-se o maior valor na ausência de $\mathrm{Zn}$ com diminuição gradual até a concentração de $5,861 \mu \mathrm{mol} \mathrm{L}^{-1}$.

Sabe-se que a morfologia e a conformação das raízes são fatores diretamente ligados para absorção eficiente de nutrientes. $E$ dependendo da disponibilidade dos nutrientes o sistema radicular tem a capacidade de mudar suas características de forma a tentar suprir determinada deficiência (Singh et al., 2005).
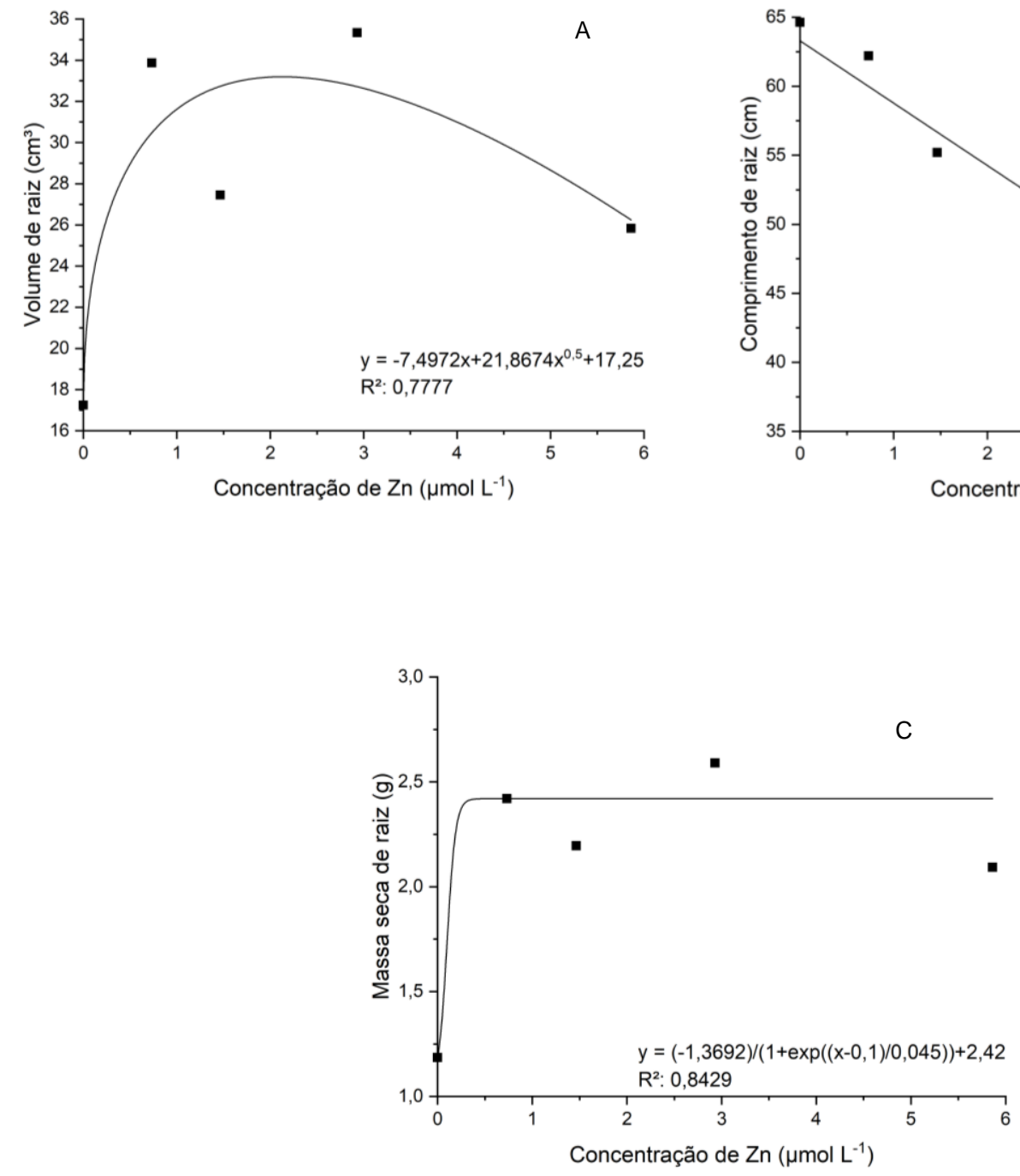

Figura 4 - Volume de raiz $(A)$, comprimento de raiz $(B)$ e massa seca de raízes de milho $(C)$, em função das concentrações de $\mathrm{Zn}$. Root volume $(A)$, root length $(B)$ and maize root dry mass $(C)$, as a function of $\mathrm{Zn}$ concentrations.

A massa seca da raiz (Figura $4 \mathrm{C}$ ) atingiu-se 0 pico na concentração de $0,733 \mu \mathrm{mol} \mathrm{L}^{-1}$ não apresentando diferenças expressivas quando comparadas com as posteriores. Assim como a variável altura de planta a dose indicada por Hoagland

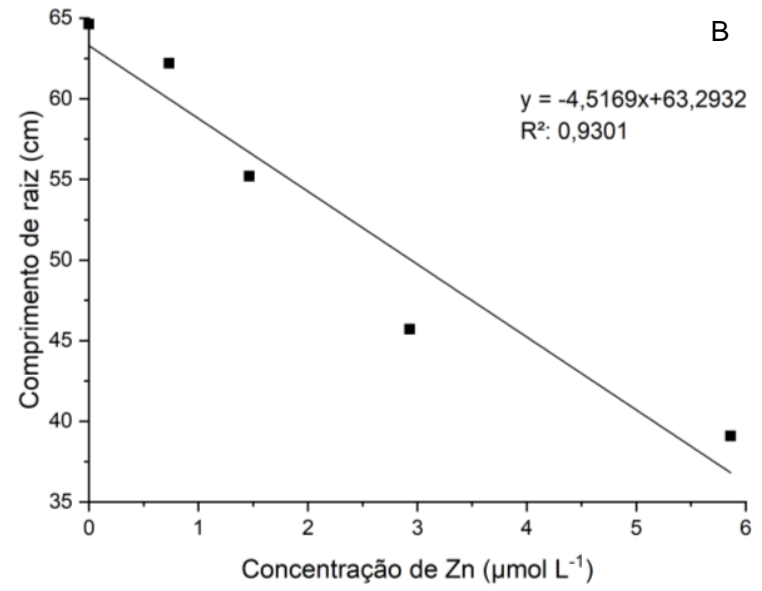

Segundo Dong et al. (1995), o crescimento e desenvolvimento das raízes depende do genótipo e das condições do solo em que a planta está submetida. $\mathrm{O}$ autor, avaliando variedades de trigo sob doses de $\mathrm{Zn}$, concluiu que raízes longas e finas são mais eficientes para a absorção do micronutriente, fato que justifica 0 maior comprimento de raízes na ausência de aplicação de $\mathrm{Zn}$ e queda linear com a aplicação de $\mathrm{Zn}$ no presente experimento (Figura $4 \mathrm{~B}$ ). Porém, vale ressaltar que na ausência de $\mathrm{Zn}$ houve menor volume de raízes, o que permite inferir que na deficiência de $\mathrm{Zn}$ a planta investiu energia no alongamento das raízes, buscando a absorção.

$B$

\section{2 \\ .}

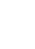


tratamento sem $\mathrm{Zn}$ e nas concentrações posteriores apresentaram valores semelhantes.

$\mathrm{O}$ teor de Fe (Figura $5 \mathrm{~B}$ ) apresentou maior valor, também, na ausência do micronutriente, no entanto, a diminuição foi linear até a maior concentração. Este fato evidencia a inibição competitiva no processo de absorção de nutrientes promovida pelo excesso de Zn na maior concentração. Sintomas típico de deficiência de $\mathrm{Fe}$, clorose paralela as nervuras das folhas novas, mantendo as nervuras verdes (Figura 6 ), foi observado nas plantas que receberam maior dose de $\mathrm{Zn}\left(5,861 \mu \mathrm{mol} \mathrm{L}^{-1}\right)$.
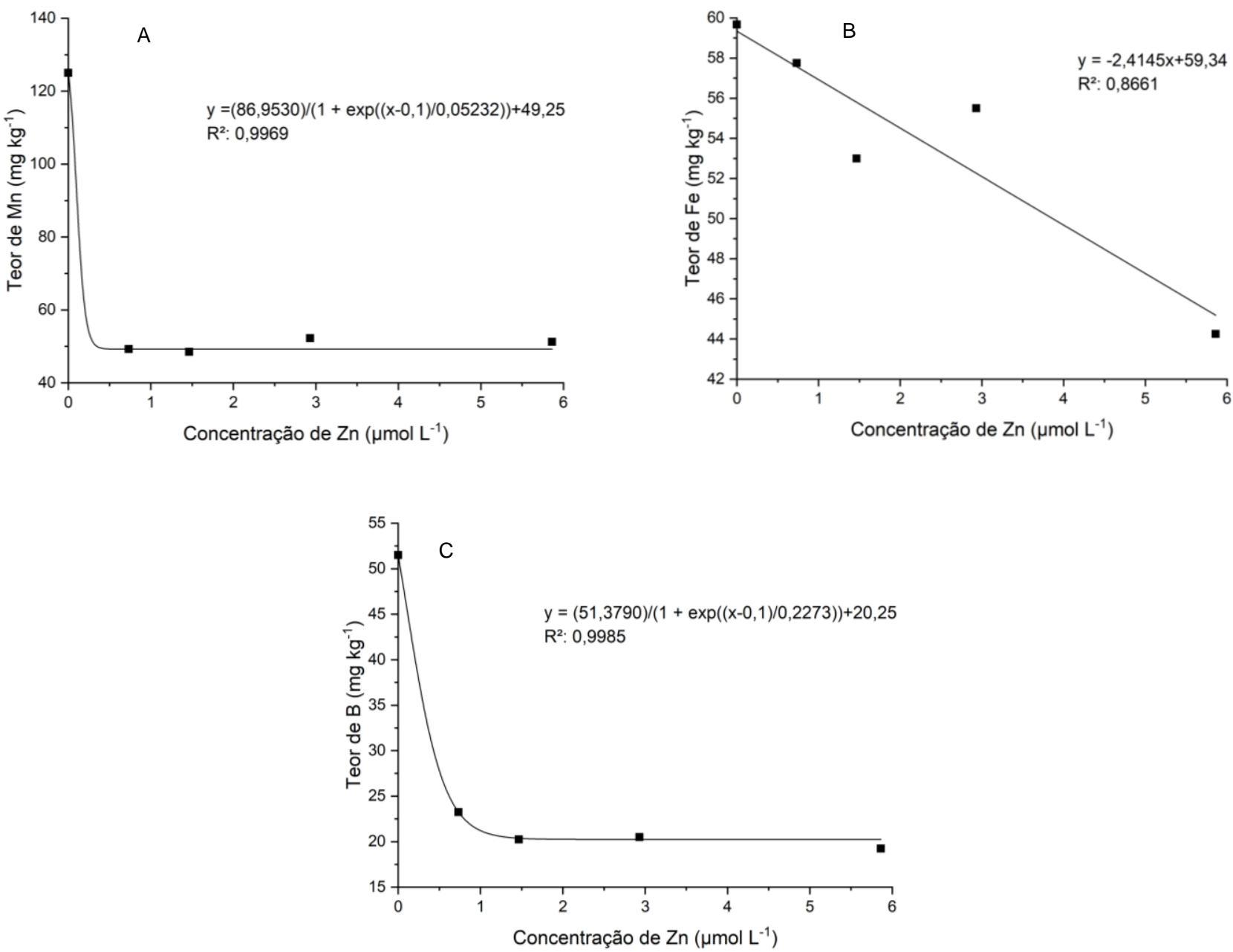

Figura 5 - Teor de $\mathrm{Mn}(\mathrm{A}), \mathrm{Fe}(\mathrm{B})$ e $\mathrm{B}(\mathrm{C})$ na massa seca de plantas de milho, em função das concentrações de $\mathrm{Zn}$. Mn (A), $\mathrm{Fe}(B)$ and $B(C)$ content in the dry mass of maize plants, as a function of $\mathrm{Zn}$ concentrations.

O maior teor de $\mathrm{Mn}$ e Fe no tratamento ausente em $\mathrm{Zn}$ está associado com a função dos micronutrientes no metabolismo. Eles atuam no sistema antioxidante e o Zn é cofator da superóxido dismutase (SOD), responsável pela conversão da espécie reativa de oxigênio $\mathrm{O}^{-}$para $\mathrm{H}_{2} \mathrm{O}_{2}$, no entanto, além do $\mathrm{Zn}$ a SOD pode ser ativada também pelo $\mathrm{Mn}$ e Fe (Mousavi et al., 2012). Dessa forma, o maior acúmulo destes pode ter ocorrido em detrimento da substituição de um micronutriente pelo outro.

Outra hipótese para o maior teor de Fe e $\mathrm{Mn}$ em plantas deficientes em $\mathrm{Zn}$ está associada com a maior produção de fitosideróforos (Rengel \& Romheld, 2000; Domingues et al., 2016). Estes são agentes quelatizantes naturais, liberados pelas raízes em condições de estresse, que formam um complexo estável (metal/fitosideróforos), solubilizando o $\mathrm{Fe} / \mathrm{Mn}$ inorgânico e transportado na planta por proteínas específicas, promovendo maior absorção.

Kanai et al. (2009) reportaram que em experimento em solução nutritiva o milho induzido a deficiência de Fe obteve um teor 16 vezes maior de $\mathrm{Zn}$ nas folhas quando comparado com o tratamento controle e 15 vezes maior na seiva do xilema. Os autores atribuíram este fato também a maior produção de fitosideróforos, uma vez que, o composto pode formar complexos estáveis com outros metais, inclusive o Zn. Além disso, foi quantificado o teor de 
tióis (-SH) que são grupamentos presentes no tripeptídeo glutationa (GHS) que atua como um dos principais antioxidantes não enzimáticos. Foi verificado que o acúmulo de $\mathrm{Zn}$ em decorrência da deficiência de
Fe aumentou a concentração de GHS indicando estresse oxidativo devido ao maior teor do micronutriente.
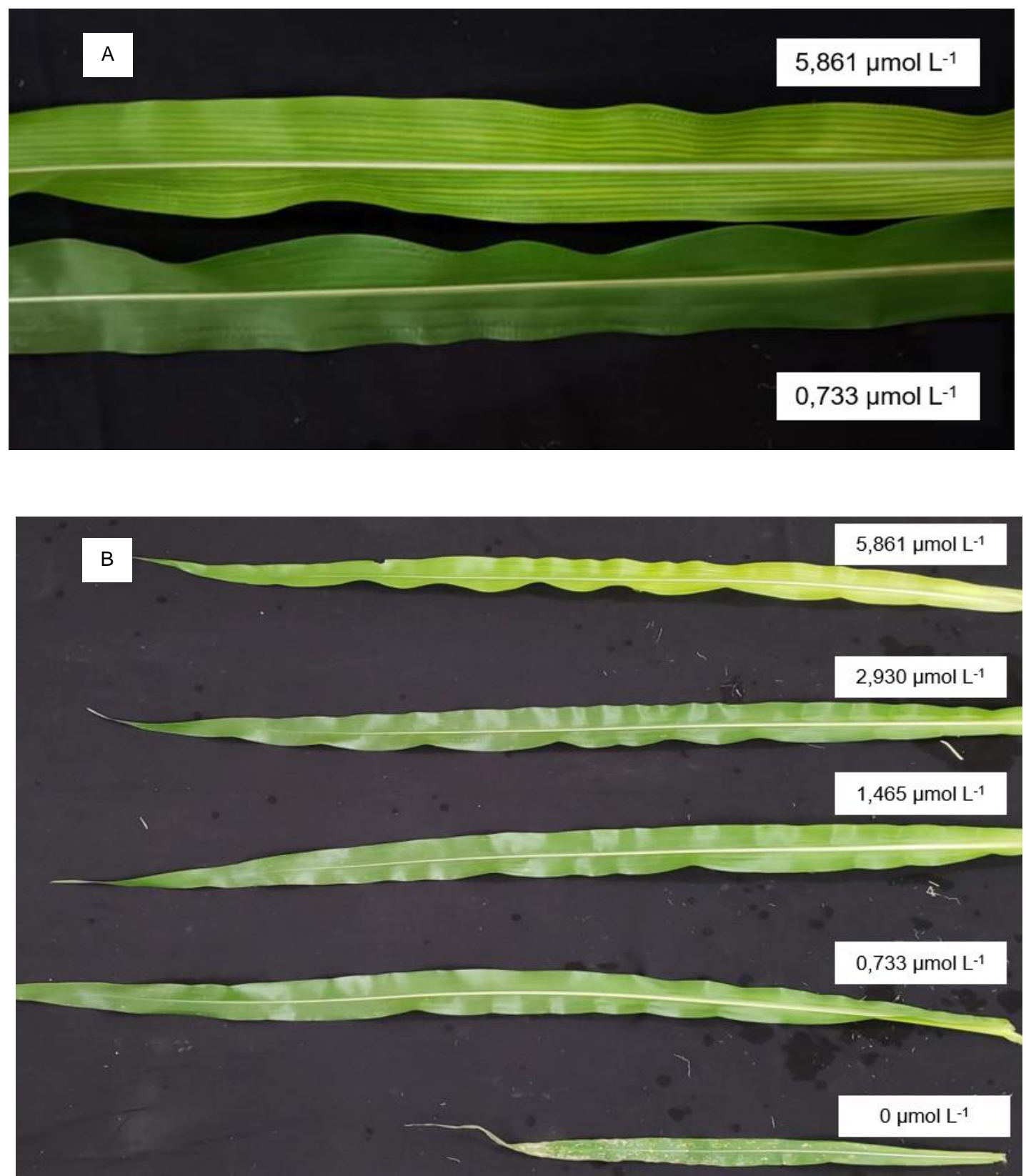

Figura 6 - Folhas de milho sob os tratamentos com 0,733 $\mu \mathrm{mol} \mathrm{L}-1$ (inferior) e com $5,861 \mu \mathrm{mol} \mathrm{L}^{-1}$ (superior) (A) e todos os tratamentos (de baixo para cima $0 ; 0,733 ; 1,465,2,930$ e $5,861 \mu \mathrm{mol} \mathrm{L}^{-1}$ respectivamente) (B). Foto: Willian Tsuyoshi Kume. Maize leaves under treatments with $0.733 \mu \mathrm{mol} \mathrm{L}^{-1}$ (bottom) and $5.861 \mu \mathrm{mol} \mathrm{L}^{-1}$ (top) (A) and all treatments (from bottom to top 0; 0.733; 1.465; 2.930 and $5.861 \mu \mathrm{mol} L^{-1}$ respectively) (B). Photo: Willian Tsuyoshi Kume 
Resultados semelhantes ao presente experimento foi verificado por Warnock (1970), no qual em experimento em casa de vegetação, observou que plantas de milho submetidas a deficiência de $\mathrm{Zn}$ acumulavam maiores teores de $\mathrm{Mn}$ e de Fe nas folhas, raízes e caule. $\mathrm{O}$ acúmulo de $\mathrm{Mn}$ em plantas deficientes foi o dobro quando comparado com o controle. Adicionalmente o maior teor de $\mathrm{Mn}$ e $\mathrm{Fe}$ também foi observado em trigo quando deficientes em Zn (Imtiaz et al., 2003).

Com relação ao teor de B (Figura $5 \mathrm{C}$ ), apesar da interação entre os micronutrientes não se amplamente descrita na literatura, estudos indicam relação inversa entre teores de $\mathrm{B}$ e $\mathrm{Zn}$ em algumas culturas. Swietlik (1995) e Hosseini et al. (2007) observaram o maior teor de B na cultura do trigo, laranja e milho, respectivamente, quando deficientes em Zn. Além disso, verificou-se nos experimentos que o aumento gradativo de doses de $\mathrm{Zn}$ diminuiu o acúmulo de $\mathrm{B}$.

Adicionalmente, o teor de B em diferentes partes de laranjeira quando deficiente em $\mathrm{Zn}$ aumenta nas folhas e diminui nas raízes quando comparado com o controle. Além disso, quando tratados com altas doses de $\mathrm{B}$ a aplicação de $\mathrm{Zn}$ aliviou os sintomas de toxidez. Este fato sugere que plantas com teores adequado de $\mathrm{Zn}$ restringe o acúmulo excessivo de $\mathrm{B}$ na parte aérea (Swietlik,1995).

\section{Conclusão}

A ausência de $Z n$ na solução nutritiva resultou em menor crescimento da planta e sintomas visuais de deficiência. Estes resultados contribuem para diagnose foliar a campo de forma a identificar a deficiência nos estágios iniciais do crescimento da cultura.

Para o milho não se recomenda a aplicação de doses maiores de $\mathrm{Zn}$ que a proposta por Hoagland e Arnon.

O excesso de $\mathrm{Zn}$ resultou em menores teores foliares de $\mathrm{Mn}$, Fe e $\mathrm{B}$ e, até mesmo, induziu a sintomas visuais de deficiência de $\mathrm{Fe}$, fato que demonstra o desbalanço nutricional nos estágios iniciais de desenvolvimento da cultura.

\section{Referências}

Amaral RD, Barros NF, Costa LM, Fontes MPF (1996) Efeito de um resíduo da indústria de zinco sobre a química de amostras de solo e plantas de milho. Revista Brasileira de Ciencia do Solo 20(3): 433-440.

Botoman L, Nalivata PC, Chimungu JG, Munthali MW, Bailey EH, Ander EL, Lark RM, Mossa A, Young SD, Broadley MR (2020) Increasing zinc concentration in maize grown under contrasting soil types in Malawi through agronomic biofortification: Trial protocol for a field experiment to detect small effect sizes. Plant Direct 4(10): 1-9.
Broadley MR, White PJ; Hammond JP, Zelko I (2007) Zinc in plants. New Phytologist 173(4): 677-702.

Domingues CRS, Barbosa JZ, Consalter R, Santos M, Adam WM, Motta ACV (2016) Influence of zinc deficiency on the mineral composition of maize plants in contrasting soils. Bioscience Journal 32(5):12341245.

Dong B, Rengel Z, Graham D (1995) Root morphology of wheat genotypes differing in zinc efficiency. Journal of plant nutrition 18(12):2761-2773.

Erturk FA, Agar G, Arslan E, Nardemir G (2015) Analysis of genetic and epigenetic effects of maize seeds in response to heavy metal (Zn) stress. Environmental Science and Pollution Research 22(13): 1- 7 .

Eteng EU, Asawalam DO (2017) Critical limits and zinc requirement for maize (zea mays I.) production in acid

soils of south-eastern Nigeria. The Nigerian Agricultural Journal 48(2): 81-92.

Fageria NK (2000) Níveis adequados e tóxicos de zinco na produção de arroz, feijão, milho, soja e trigo em solo de cerrado. Revista Brasileira de Engenharia Agrícola e Ambiental 4(3): 390-395.

Fernandes TJ, Pereira AA, Muniz JA, Savian TV (2014) Seleção de modelos não lineares para a descrição das curvas de crescimento do frito do cafeeiro. Cofee Science 9(2):207-215.

Ferreira DF (2011) Sisvar: um sistema computacional de análise estatística. Ciência e Agrotecnologia, 35(6):1039-1042.

Fiesp. Safra Mundial de Milho 2018/19 - 10 levantamento do USDA. Federação das indústrias do estado de São Paulo. Disponível em: $<$ https://www.fiesp.com.br/indices-pesquisas-epublicacoes/safra-mundial-de-milho-2/attachment/file20190208195749-_boletimmilhofevereiro2019/>. (Acesso em 27 fev 2019).

Galrão EZ (1994). Métodos de correção de deficiência de zinco para a cultura do milho em um Latossolo Vermelho-Escuro argiloso sob o Cerrado. Revista Brasileira de Ciência do Solo 18(2): 229-233.

Gondim AR, Prado RM, Fonseca IM, Alves AU (2016) Crescimento inicial do milho cultivar brs 1030 sob omissão de nutrientes em solução nutritiva. Revista Ceres 63(5):706-714.

Gupta N, Ram H, Kumar B (2016) Mechanism of Zinc absorption in plants: uptake, transport, translocation and accumulation. Reviews in Environmental Science 15: 89-109. 
Hoagland DR, Arnon DI (1950) The water culture method for growing plants without soils. California Agricultural Experimental Station 347p.

Hosseini SM, Maftoun M, Karimian N, Ronaghi A, Emam $Y$ (2007) Effect of zinc $x$ boron interaction on plant growth and tissue nutrient concentratiron of corn. Journal of plant nutrition 30(5):773-781.

Hosseini Z, Poorakbar L (2013) Zinc toxicity on antioxidative response in (Zea mays L.) at two different $\mathrm{pH}$. Journal of Stress Physiology \& Biochemistry 9(1):66-73.

Imtiaz M, Alloway BJ, Shah KH, Siddiqui SH, Memon MY, Aslam M (2003) Zinc nutrition of wheat: II: interaction of zinc with other trace elements. Asian J. Plant Sci 2(2):156-160.

Islam F, Yasmeen T, Riaz M, Arif MS, Ali S, Raza SH (2014) Proteus mirabilis alleviates zinc toxicity by preventing oxidative stress in maize (Zea mays) plants. Ecotoxicology and Environmental Safety 110: 143-152.
Kanai M, Hirai M, Yoshiba M, Tadano T, Higuchi K (2009) Iron deficiency causes zinc excess in Zea mays. Soil Science and Plant Nutrition 55: 271-276.

Kumar L, Meena NLS, Singh U (2016). Role of Phytosiderophores in Acquisition of Iron and Other Micronutrients in Food Legumes. In: SINGH, U.; PRAHARAJ, C. S. (ed) Biofortification of food crops, Springer. p.291-302.

Leite UT, Aquino BF, Rocha RNC, Silva J (2003) Níveis críticos foliares de Boro, Cobre, Manganês e Zinco em milho. Bioscience Journal 19(2): 115-125.

Mousavi SR, Galavi M, Rezaei M (2012) The interaction of zinc with other elements in plants:a review. International Journal of Agriculture and Crop Sciences 4(24):1881-1884.

Nguyen NT, Mclnturf SA, Mendoza-Cózatl DG (2016) Hydroponics: A Versatile System to Study Nutrient Allocation and Plant Responses to Nutrient Availability and Exposure to Toxic Elements. Journal of Visualized Experiments 113: 1-9. 